NOTICE: This is the author's version of a work that was accepted for publication in Food Control. Changes resulting from the publishing process, such as peer review, editing, corrections, structural formatting, and other quality control mechanisms may not be reflected in this document. Changes may have been made to this work since it was submitted for publication. A definitive version was subsequently published in Food Control, Vol. 31, Issue 2, (2013). doi: 10.1016/j.foodcont.2012.10.027 


\section{Predicting adolescents' safe food handling using an extended theory of planned behavior}

Barbara A Mullan ${ }^{\mathrm{a}}$

Cara Wong ${ }^{\mathrm{a}}$

Emily J Kothe ${ }^{\mathrm{a} 1}$

aSchool of Psychology, The University of Sydney, Sydney, Australia

${ }^{1}$ Present address: School of Psychology, Deakin University, Melbourne, Australia

Corresponding author at: Barbara Mullan, Room 446 Brennan MacCallum (A19), The School of Psychology, The University of Sydney, NSW 2006, Australia. Ph: +61 29351 6811. Email: barbara.mullan@sydney.edu.au

Cite as: Mullan, B. A., Wong, C., Kothe, E.J., (In Press). Predicting adolescents' safe food handling using an extended theory of planned behavior. Food Control. 


\section{Highlights}

- Knowledge predicts $4 \%$ of the variance in food hygiene intention

- Together TPB and risk predict a further $60 \%$ of the variance in intention

- Risk perception adds to the prediction of intention over TPB constructs

- Knowledge predicts $1.4 \%$ of the variance in food hygiene behavior

- Intention and PBC predict a further $24 \%$ of the variance in behavior 
The aim of this study was to investigate whether the Theory of Planned Behavior (TPB) with the addition of risk perception could predict safe food handling in a sample of adolescents from the UK and Australia over and above the explanatory power of knowledge. It was hypothesized that knowledge would predict both intention to prepare food safely and selfreported food hygiene behavior. It was expected that attitudes, subjective norm, perceived behavioral control and risk perception would predict intentions over and above knowledge. It was hypothesized that intentions and PBC would significantly predict food hygiene behavior over and above the influence of knowledge. Participants were recruited from secondary schools in Australia and the UK $(n=205)$. Knowledge alone predicted 4\% of intention and $1.4 \%$ of behaviour. TPB variable with the addition of risk perception accounted for an additional $60 \%$ of the variance in intention. PBC and intention accounted for an additional $24 \%$ of the variance in behavior. Knowledge was not a significant predictor of intention or behaviour once other variables were added to the model these results provide further support for criticisms of interventions that have targeted food safety through knowledge based interventions. The results provide further support for the utility of the TPB in predicting safe food handling. The addition of risk perception added to the predictive utility of the model, suggesting that researchers may want to incorporate that factor into future considerations of food hygiene using the TPB. 


\section{Introduction}

\subsection{Food hygiene, the extent/ prevalence of the problem}

Approximately one in four Australians experience foodborne illness each year - with over 5.4 million cases of food poisoning estimated annually (Hall, et al., 2005). This is consistent with data from the USA in 1999 (Mead, et al., 1999), which estimated of 76 million cases, giving rates of just over one in four. Rates are lower in the UK, where it was estimated that there were 926,000 cases of foodborne disease in 2007 (Food Standards Agency, 2009).

Furthermore, these figures are likely to underestimate the true incidence of foodborne disease due to under-reporting (Crerar, Dalton, Longbottom, \& Kraa, 1996). The high incidence of foodborne illness has serious implications for public health (Hall \& Kirk, 2005) and represents a significant financial burden including ill-health, sick leave and death (Desmarchelier, 1996). For example, costs in Australia are approximately $\$ 1.25$ billion annually, including an average of 120 deaths a year (Food Authority NSW, 2008) and in the UK are approximately $£ 1.5$ billion annually (Food Standards Agency, 2005), including an average of 687 deaths per year (Adak, Meakins, Yip, Lopman, \& O'Brien, 2005).

A large proportion of foodborne illness originates in the home (Ryan, Wall, Gilbert, Griffin, \& Rowe, 1996), with research demonstrating that consumers do not implement safe food handling practices (Brennan, McCarthy, \& Ritson, 2007; Jay, Comar, \& Govenlock, 1999; Redmond \& Griffith, 2003a). Further, childhood is an important time for developing knowledge and skills about food hygiene and preparation. However, teaching of these skills in schools appears to be declining. For example, teaching of food hygiene is not included in the national curriculum in England and Wales (Mullan, 2009). Very little attention has been given to children and adolescents' food handling practices, even though they prepare food regularly. For example, one study found that $95 \%$ of middle-school children helped to 
prepare food (Byrd-Bredbenner, Abbot, \& Quick, 2010), whilst another found that $92 \%$ of middle school children prepared meals or snacks at home (Haapala \& Probart, 2004). In addition, children and adolescents will become responsible for food shopping and preparation in the future (Byrd-Bredbenner, et al., 2010). A study in the USA looking at middle school children (mean age 12) found that although students had a basic and fairly broad knowledge base related to safe food handling, they had limited comprehension as to why safe food handling is important and how to practice safe food handling (Byrd-Bredbenner, et al., 2010). In order to improve food hygiene practices, particularly in adolescents, it is important to understand the underlying factors that contribute to behavior.

\subsection{The role of knowledge}

One explanation for poor food handling in the home is lack of knowledge. Increasing knowledge can allow the consumer to make more informed behavioural choices. Indeed, the majority of interventions to prevent foodborne illness have focused on education (Milton \& Mullan, 2010), in the belief that failure to engage in food hygiene behavior is the result of inadequate food safety knowledge (Griffith, Worsfold, \& Mitchell, 1998). Empirical studies provided mixed support for this interpretation. Some studies have found that knowledge is the most important predictor of compliance with safe food handling (Abbot, Byrd-Bredbenner, Schaffner, Bruhn, \& Blalock, 2009), and knowledge is limited in young adult populations (Giritlioglu, Batman, \& Tetik, 2011; Osaili, Obeidat, Abu Jamous, \& Bawadi, 2011). However, many studies have demonstrated a discrepancy between knowledge and food hygiene behaviour (Clayton, Griffith, \& Price, 2003; Harris \& Mullan, 2009; Mullan, 2010; Soon, Baines, \& Seaman, 2012). Research with children is limited. For example, one study which used children's assessment of their food hygiene knowledge found that although 97\% of their sample of young adults rated their own food safety knowledge as at least fair, $60 \%$ did not wash their hands with soap and water after touching raw poultry (Byrd-Bredbenner, 
Maurer, Wheatley, Cottone, \& Clancy, 2007). One study that measured actual food hygiene knowledge suggested that food safety knowledge in middle school children was only moderate, and that there was a disconnect between knowledge and behavior (Haapala \& Probart, 2004). Therefore other variables that may also contribute to predicting and changing safe food handling practices must be investigated. In addition, other variables may interact with knowledge to better predict food hygiene behaviours.

\subsection{The role of other variables in explaining food hygiene}

Thus most research concludes that while knowledge is an important element in food hygiene, knowledge alone does not lead to safe food handling behaviour (Harris \& Mullan, 2009; Mullan, 2010). Social cognition models from the realm of health psychology have been frequently posited as an important tool in improving both prediction and intervention research in safe food handling (Griffith, Mullan, \& Price, 1995; Mullan, 2010; Rennie, 1995). One such model is the health belief model (Rosenstock, 1974); which considers barriers and benefits of engaging in safe food handling as well as how severe food poisoning is seen to be and the degree of susceptibility to the illness. Within the arena of food hygiene some studies have found this model to be useful with older adults (Hanson \& Benedict, 2002) but not with younger adults (McArthur, Holbert, \& Forsythe, 2006). There has also been more general criticism of the model in the wider health arena. For example a meta-analysis of the model (Harrison, Mullen, \& Green, 1992) concluded that there were weak effect sizes and poor homogeneity of the variables within studies. A later meta-analysis suggested that due to the weakness of two of the predictors, the health belief model as it is currently conceived should not be used (Mente, de Koning, Shannon, \& Anand, 2009).

Another more frequently applied social cognition model is the theory of planned behavior (TPB; Ajzen, 1991). The theory of planned behavior posits that the most important 
determinant of behavior is intention, whereas intention in turn, is predicated by attitude, subjective norm and perceived behavioral control (PBC; Ajzen, 1991). Attitude is a measure of the degree to which a person has a favourable or unfavourable evaluation towards the behavior, such that when a person thinks that preparing and handling food hygienically is important and necessary, they are more likely to intend to engage in behavior. Subjective norm represents the normative influences or the perceived social pressure to perform or not perform the behavior. In the case of food hygiene, if an individual believes that important people such as parents or friends think that food hygiene behaviors are important, they are more likely to intend to perform these behaviors. Finally PBC represents the individual's perceptions of the ease or difficulty of performing the behavior of interest. Thus, if a person has the necessary materials to prepare food hygienically, and finds the behavior easy, they are more likely to have strong intentions to perform the behaviour. PBC can influence both intentions and behavior, in that when a behavior is under not under volitional control PBC can directly affect behavior.

A number of studies have looked at safe food handling using the TPB. For example, Clayton et al (2003) found that the TPB explained 34\% of the variance in hand hygiene malpractices in the workplace, and Seaman and Eves (2010) found the model successfully predicted food safety practices in small food businesses. Clayton and Griffith (2008) used social cognition models to predict safe hand washing, and found the TPB was the most appropriate model. Mullan \& Wong (2009) applied the theory to the prediction of consumer food handling practices in a population of Australian young adults. That study found that the TPB constructs predicted $66 \%$ of the variance in intention and $21 \%$ of the variance in behavior. More recently, a study investigating prediction of intentions to adopt safe home food handling practices including hand washing and food thermometer use (Shapiro, Porticella, Jiang, \& Gravani, 2011). The TPB explained $42 \%$ of the variance in intention to 
wash hands and $43 \%$ of the variance in intention to use food thermometers. PBC was the most significant predictor of intentions. Few studies have considered children within this theoretical framework. However, a series of studies by Mullan (Mullan, 1998, 2009) have indicated that intention is a significant predictor of children's safe food handling behaviors. Together these studies clearly show that the TPB can be successfully applied to the prediction of food hygiene behaviors.

Although the TPB has shown relative success in predicting food hygiene practices, it has some limitations that need to be considered. Firstly, the current body of literature does not discern whether the TPB variables can predict intention and behavior over and above knowledge. It has been argued that knowledge alone is not sufficient for behavior to be performed but whether it can or should be incorporated into existing models of health behavior has not been explored in detail. Fishbein and Azjen (2010) argue that there are only at best modest correlations between knowledge and behavior. However, in the case of food hygiene, knowledge importantly pertains to how to perform behaviors correctly (e.g. you should not cut meat and vegetables on the same chopping board), rather than general knowledge that may be related to other health behaviors (e.g. what proportion of breast cancer occurs in women over 50). Therefore, knowledge in this particular behavior may be more important in actually performing behaviors correctly to reduce the risk of foodborne illness.

$$
\text { Secondly, there is usually a large proportion of variance unaccounted for in both }
$$
intentions and behavior. Consequently, the TPB is open to the inclusion of additional variables that may increase the proportion of variance in behavior explained. Risk perception may be an important factor, particularly in the food hygiene domain. Perceptions of food safety risks may contribute to shape and guide an individual's decisions and behavior (Frewer, Shepherd, \& Sparks, 1994), particularly since risk estimates tend to be lower than 
actual risk (Clayton, Griffith, Price, \& Peters, 2002). Perceived risk of disease is thought to be an important motivation for action (Redmond \& Griffith, 2004). Particularly in the domain of food hygiene as there are many risks involved in unsafe food handling including food poisoning and even death.

Accordingly, it has been found that individuals with higher perceived risks reported safer food handling behavior (Roseman \& Kurzynske, 2006). This has led to many health interventions that use fear-arousing communications regarding food safety (Kuttschreuter, 2006). The problem with this however, is that the threat may be perceived as irrelevant or insignificant, thus making these campaigns ineffective. Optimism bias is a well documented phenomenon which suggest that individuals may underestimate the likelihood that they will encounter negative consequences from partaking in risky health behavior. In a study of middle school students, perceptions of severity of foodborne illness were high, but the score for perceived personal susceptibility was low (Haapala \& Probart, 2004). Similar finding in adults have been reported (Redmond \& Griffith, Frewer, et al., 1994; 2003b) and suggest that those with low personal susceptibility will be less likely to take preventative action. Therefore, it is not only the perceived risk severity but also the individual's perceived vulnerability to the risk that may be important in predicting of behavior.

One of the models of health behavior that includes a measure of risk is the health 
before preparing a meal". Finally risk severity measures how severe the individual perceives the negative consequence to be.

Two studies that have used the HAPA to predict food hygiene found that risk severity had a low correlation with risk vulnerability practices (Chow \& Mullan, 2010; Mullan, Wong, \& O'Moore, 2010). This supports the contention that there is a discrepancy between severity and vulnerability, particularly in the context of food hygiene. Due to the low internal consistencies between the risk components, Chow and Mullan (2010) and Mullan et al (2010) separated the components. Both studies found that only absolute risk was significant in predicting intention, along with other HAPA variables of self efficacy and outcome expectancies. Chow and Mullan (2010) found risk vulnerability to be the strongest predictor of intentions. However, the authors also included a social norm component from the TPB and found that it significantly improved the proportion of variance explained in intentions. This suggests that normative and risk cognitions are important in food hygiene, however, there is currently no model that includes both these components.

Very few studies have included risk perception as an additional variable to the TPB in predicting intention and behavior. Lobb, Mazzocchi and Train (2007) added risk perception to the TPB in predicting intention to purchase chicken. They found a significant interaction between risk perception and attitudes in predicting intention. The TPB study by Mullan and Wong (2009) found that normative influences and PBC from the TPB were important in predicting intention, whilst the later HAPA study found that risk perception and self-efficacy were influential factors in food hygiene behaviors. Therefore the current study will include risk perception as an additional variable to the TPB in predicting intentions to perform safe food handling. 

hygiene in a sample of adolescents recruited from the UK and Australia. In addition, food hygiene knowledge and risk perception were included as previous research has identified these variables as being important in food handling behaviors. It was hypothesized that knowledge would predict both intention to prepare food safely and self-reported food hygiene behaviour. However, it was expected that the TPB variables of attitudes, subjective norm and PBC would predict intentions, and that risk perception would increase the proportion of variance explained. Secondly, in line with the TPB, it was hypothesized that intentions and PBC would significantly predict food hygiene behavior over and above the influence of knowledge. It was expected that there would be an interaction between food knowledge and intention, such that greater knowledge and stronger intentions to engage in food hygiene behavior would increase actual food hygiene behavior beyond the individual contribution of these constructs.

\section{Methods}

\subsection{Recruitment.}

Participants were 11-18 year olds recruited from secondary schools in Australia and the United Kingdom. Three Australian schools participated from the state of New South Wales (NSW). Four schools from the UK participated in the study from a range of areas including Worcestershire, Gloucestershire, Yorkshire and Hampshire. Due to time and workload constraints of older students, the majority of schools agreed that students aged 14-15 could participate. The University Research Ethics Committee approved the study.

\subsection{Questionnaires.}


238 The TPB questionnaire was developed and informed by guidelines for the construction of 239 TPB questionnaires (Francis, et al., 2004) and based on items used by Mullan and Wong 240 (2009) and Mullan (2009). The risk perception measure was adapted from Shwarzer et al's 241 HAPA model (2003) and Chow and Mullan (2010).

242 Attitudes were assessed as the mean of six semantic differential scales (e.g. preparing food hygienically every meal would be: bad-good, unnecessary-necessary, unpleasant-pleasant, unenjoyable- enjoyable, beneficial-harmful, foolish-wise). Participants rated on a scale of 17 with a higher score indicating a more positive attitude. A Cronbach's alpha coefficient of .93 was reported.

Subjective norm was assessed by a single item " people who are important to me think I should prepare food hygienically every meal over the next 4 weeks'" (unlikely-likely), scored 1-7 with a higher score indicating more normative pressure.

PBC was assessed as the mean of four, seven-point (1-7) items including two items for controllability and two for self-efficacy. This is because the internal reliability of PBC items has frequently been found to be low (e.g. Ajzen, 2002; Sparks, 1994), therefore more than one measure of controllability is now recommended. For this variable a Cronbach's alpha coefficient of .89 was reported.

Risk Perception was measured with three risk components - relative risk, absolute risk and risk severity. Absolute risk was measured with three items (if you don't prepare food hygienically every meal, how do you estimate the likelihood that you will ever: suffer from food poisoning/ will feel less healthy/ will not eat your food). This was measured on a 7 point Likert scale from very low to very high. A cronbach's alpha coefficient of .84 was reported. Relative risk was measured by asking participants, compared to other people of your age and sex, if you don't prepare food hygienically every meal how do you estimate the likelihood 
that you will ever: suffer from food poisoning/ will feel less healthy/ will not eat your food. An alpha coefficient of .90 was reported. The third component measured was risk severity (How severe would the following health related problems be for you, to suffer from food poisoning/ to feel less healthy/ to be unable to eat your food). An alpha coefficient of .83 was reported. The combined effect of absolute, relative risk and risk severity had an alpha coefficient of .90 .

Intention was assessed as the mean of four items, each measured on seven-point scales (I intend/plan/aim/will make an effort to prepare food hygienically every meal over the next 4 weeks). For intention the alpha coefficient was .96 $(\mathrm{M}=5.5, \mathrm{SD}=1.6)$.

Behavior was measured by asking participants how many times per week during the previous 4 weeks, they had prepared food hygienically on a scale of 1-8 (never to 7 times a week). Hygienic food handling was defined as 'an action taken to ensure that food is handled, stored, prepared and served in such a way to prevent contamination of food'.

Knowledge was measured using the Byrd-Bredbenner et al (2007) Food Safety Knowledge Questionnaire. This measure has been validated and is a standardised self-report questionnaire with multiple choice answers (choose out of 5 possible answers; or true/false). It is scored out of 89 and assesses knowledge across five food hygiene sub-scales including: cross-contamination prevention and disinfection procedures; time and temperature for cooking and storing food; the groups at greatest risk for foodborne diseases; foods that increase the risk of foodborne diseases; and common food sources of foodborne disease pathogens. Participants receive a score for each correct response or true/false response. Total scores were calculated as a percentage.

\subsection{Procedure}


285 Teachers from participating schools assisted the researchers in administering the online task

286 by providing students with the relevant questionnaire URL and issuing individual participant

287 IDs. Participants completed all measures in one sitting.

$288 \quad 2.4$ Analysis

289 Data were analysed using SPSS version 15. Hierarchical regression analyses were run to 290 analyse the predictive influence of each of the variables on intention and behavior. In the first 291 regression predicting intention, knowledge was entered in the first block, TPB variables of 292 attitude, subjective norm, and PBC were entered in the second block and risk perception 293 scores in the last block. In a second regression predicting behavior, knowledge was entered 294 first, followed by intention and PBC in the second block. Exploratory analyses were run to 295 investigate any demographic differences in food hygiene knowledge and behavior.

\section{3. Results}

297 A total of 205 participants completed the study. There were 91 males and 114 females, with a 298 mean age of 13.7 years $(\mathrm{SD}=1.38)$. Demographics are presented in Table 1. 
A table of Pearson's bivariate correlations between all cognitive variables and behavior are shown below in Table 2. In terms of food hygiene, seven percent of participants reported that they never handled food hygienically. Only $38 \%$ of the participants claimed that they always handled food hygienically. One-way ANOVAs were run to investigate whether there were any demographic differences in behavior. No significant effects were found for gender or country (UK versus Australia). Significant effects were found for SES from father's occupation $(\mathrm{F} 2,197=6.49, \mathrm{p}=.002)$. Post-hoc Tukey comparisons showed that the significant difference was between middle and high SES ( $p=.002)$, where those of high SES tended to report more frequent hygienic food preparation. Food safety knowledge was very low with a mean of $42 \%$ of items correct $(\mathrm{SD}=12.6$, range $10-77 \%)$.

\subsection{Predicting intention}

In a hierarchical regression analysis, knowledge was entered in the first step in predicting intention (see Table 3). The results showed that knowledge alone predicted $4 \%$ of intention, a small but significant proportion of variance $\left(\mathrm{F}_{1,203}=8.55, \mathrm{p}=.004\right)$. In step 2 , the TPB variables were added and the analyses showed that together knowledge, attitude, subjective norm and PBC predicted $63.7 \%$ of the intentions to prepare and handle food hygienically. However, only subjective norm and PBC were significant predictors of intention, whilst attitudes and knowledge were not. In the last step of the regression, risk perception was included. It was found that risk was a significant predictor of intention, and increased the proportion of variance explained by $1.1 \%$ to $64.8 \%\left(\mathrm{R}^{2} \Delta=.011, \mathrm{~F} \Delta_{1,198}=6.19, \mathrm{p}=.014\right)$. 


\subsection{Predicting behavior}

326 A hierarchical regression analysis was carried out to investigate the additive effects of

327 knowledge and the TPB variables in predicting behavior. In the first step, knowledge alone 328 predicted $1.4 \%$ of behavior. The TPB variables of intention and PBC were then added and 329 were significant in predicting behavior. Intention and PBC predicted a further $23.3 \%$ of 330 variance in food hygiene behavior with PBC as the strongest predictor of behavior. To investigate whether knowledge could moderate the relationship between intention and behavior, the intention and knowledge scores were mean centred and an interaction variable created. This was entered into the regression in the final step. However, there was no significant moderating effect of knowledge (see Table 4).

\section{$<<$ Table 4 about here $>>$}

\section{Discussion}

The current study was the first to apply the TPB model in predicting food hygiene behaviors in an adolescent population. Food safety practices in this population have rarely been studied despite the fact that adolescents prepare meals regularly (Byrd-Bredbenner, et al., 2010; Haapala \& Probart, 2004) and this is an important time for developing knowledge and skills about food hygiene and preparation. In addition, food safety knowledge and risk perception were investigated as they have been shown to influence food safety behavior.

\subsection{Predicting intention}


The results showed that knowledge alone predicted $4 \%$ of intention and almost $2 \%$ of behavior. Although these were small proportions, knowledge was a significant predictor of food handling intention and behavior in adolescents. Previous research has reported that knowledge is one of the best predictors of compliance with safe food-handling practices (Abbot, et al., 2009) However, in the current study, once the TPB variables were included into the analyses, knowledge was no longer significant. This is in line with the general argument that knowledge is a necessary but not sufficient condition for behavior to be performed (Fishbein \& Ajzen, 2010). Fishbein and Azjen (2010) argue that knowledge should be related to motivational factors such as attitudes, subjective norm and PBC rather than behavior. However, knowledge was only weakly correlated with all of the TPB variables and did not mediate the intention-behavior relationship. These data suggests that alone, knowledge has a small direct effect on intention and behavior to perform safe food handling, however it is outweighed by social cognitive factors. The majority of food hygiene interventions previously have focused on education, using persuasive messages and targeting increasing knowledge, it only led to change in two out of nine behavioral outcomes (Dharod, Perez-Escamilla, Bermudez-Millan, Segura-Perez, \& Damio, 2004). This suggests that interventions need to move the focus away from just increasing knowledge. One example of a successful theory based food hygiene intervention in young adults (Milton \& Mullan, 2010) could be replicated in adolescents.

After controlling for knowledge scores, the TPB variables of attitude, subjective norm and PBC significantly increased the proportion of variance explained to $63.7 \%$. This is similar to findings in adult populations, where the TPB variables were found to predict $66 \%$ of the variance in intention (Mullan \& Wong, 2009). Further, subjective norm and PBC 
significantly predicted intention, whilst attitudes did not following a similar pattern to that found by Mullan and Wong (2009). This finding is in contrast to the majority of studies that have found subjective norm to be the weakest variable in predicting intention (Conner \& Sparks, 2005). The current study found that subjective norm was the most significant predictor of intention. Taken together, the previous and current findings suggest that at least in the case of food hygiene, social normative influences are more important than individual attitudes towards food handling across a range of ages. This was supported by Chow and Mullan (2010) who included subjective norm as an additional variable to the HAPA model. They also found that subjective norm was the most significant predictor of intentions to practice food safety behaviors suggesting that development of intentions to adopt safe food handling depends in part, on the expectations of significant others including parents, friends, the media, and health experts. Quine, Rutter and Arnold (1998) suggested that normative influences would be higher in behaviors that can affect the health of others and are performed in public. This is applicable to food hygiene behaviors, and particularly adolescents may feel more inclined to feel social pressures to perform or not perform health behaviors compared to adults. This also confirms the importance of targeting this age group when food safety behaviors are likely being taught by primary caregivers. Consequently, food safety interventions should consider normative influences and also involve and educate significant others.

Risk perception was included as an additional variable to the TPB as it has previously been shown that it is an important factor in predicting health behaviors (Schwarzer, et al., 2003). Risk can also be separated into severity and vulnerability and these two components have been shown to be differentially associated with food hygiene behaviors (Chow \& Mullan, 2010; Haapala \& Probart, 2004; Mullan, et al., 2010). However, in contrast to previous studies, the results showed that severity, absolute and relative (vulnerability) risks 
were all highly correlated $(r=.9)$, thus representing a unitary construct. In line with the hypothesis, risk perception was shown to be a significant predictor of intentions to perform safe food handling and made a small but significant increase in the proportion of variance explained. The findings suggest that at least in adolescent populations, perceptions of severity as well as vulnerability to specific risks of not handling food hygienically can influence their food hygiene practices. A previous study similarly found a relationship between risk perception and safe food handling such that those with lower perceived risk practiced less hygienic behaviors (Roseman \& Kurzynske, 2006). Risk was similarly significantly correlated with both intentions and behaviors, and suggests that increasing risk perception including personal vulnerability and risk outcomes could lead to behavioral change.

However, correlational studies such as that by Roseman and Kurzynske (2006) do not show the causal effect of cognitions on behavior. In the current regression model, risk perception only contributed a small proportion of variance in explaining intentions compared to the TPB variables.

\subsection{Predicting behavior}

The direct effect of knowledge on behavior was also investigated as a number of intervention studies have been based on the presumption that increasing knowledge will lead to increased food hygiene practices (Cody \& Hogue, 2003; Dharod, et al., 2004) and has been acknowledged as an essential prerequisite for engaging in safe food handling (Green \& Selman, 2005). The current study found that alone, knowledge was a significant predictor of behavior explaining $2 \%$ of the variance in behavior. However, once the TPB variables of intention and PBC were entered into the regression, knowledge was rendered non-significant. This further highlights the argument that whilst knowledge may be necessary for engaging in hygienic food handling procedures, it is not sufficient for changing behavior (Raab \& Woodburn, 1997; Wilcock, Pun, Khanona, \& Aung, 2004). This gap was partially closed by 
the TPB which predicted $23.3 \%$ of the variance in behavior. This is comparable to previous

420 findings using the TPB (Fulham \& Mullan, 2011; Mullan \& Wong, 2009). However, in an

421 adolescent population, PBC appeared to be most influential over behavior. The findings

422 suggest that the ease or difficulty of performing a behavior will have a direct influence over

423 whether food safety practices are performed, over and above intentions. For example, even

424 though an individual may intend to handle food hygienically, if they do not have the

425 necessary abilities/tools and are faced with barriers, then they are less likely to perform

426 behavior. A recent intervention study on a university-aged sample by Milton and Mullan

427 (2012) increased PBC by asking participants to identify barriers that impeded performance of

428 food safety behavior, then generate plans to overcome these. The intervention group

429 performed significantly higher numbers of correct observed food hygiene behaviors at

430 follow-up. The current findings support the need to introduce PBC based interventions in

431 adolescents; however, these may need to be tailored to be more age appropriate.

Like many studies which have applied to the theory of planned behaviour to the prediction of behaviour (Armitage \& Conner, 2001), this study was more successful at predicting intention than behaviour. This suggests that some individuals fail to engage in intended food hygiene practices. Future researchers may wish to consider how to best bridge this 'intention-behaviour gap' in order to better translate intentions into behaviour.

\subsection{Limitations and future directions}

This study is a significant addition to the literature, in that it is one of the few to investigate predictors of food hygiene in children and adolescents. However, care should be taken when interpreting these results. Firstly, food hygiene behavior was measured via a self report measure in the current study. While the use of self report measures is often seen as a limitation in research into safe food handling, recent research has shown that self report significantly correlates with observed food hygiene behavior (Milton \& Mullan, 2012), this 
combined with the practicality of using online data collection deems self report data

collection very acceptable. Researchers should be aware of the relative advantages and across participants, and therefore question order may have influenced the results. Thirdly, as with many previous studies, this study sample was slightly less demographically diverse than the population from which it was drawn. This should be taken into account when attempting to generalize these findings to the broader population. Researchers may wish to consider how other sampling methodologies (e.g. stratified sampling) may widen sociodemographic diversity in future samples. Finally, direct measures of TPB constructs were used in the current study. Whilst this was considered appropriate given the broad measure of behavior, further studies could use elicitation interviews to explore more specific constructs and behaviors relevant to this population. hygiene literature, and suggests that the TPB and risk factors are important to consider when explaining safe food handling practices. The body of literature to date could benefit from future studies exploring the specific types of attitudes, norms, control perceptions and risk factors that are relevant to this age group, to aid specific intervention design within this population.

\section{Conclusion}

464 The current study is one of the few to apply the TPB to the prediction of food safety 465 behaviours in children and adolescents, and the first to consider the contribution of 466 knowledge and risk perception to the prediction of food hygiene intentions and behaviours in this population. The results provide further support for the utility of the TPB in predicting 
468 safe food handling. The results also indicate that once other factors are taken into account,

469 knowledge is not a significant predictor of food hygiene behavior; providing further support

470 for criticisms of interventions that have targeted food safety through knowledge based

471 interventions. The addition of risk perception added to the predictive utility of the model,

472 suggesting that researchers may want to incorporate that factor into future considerations of

473 food hygiene using the TPB. 
476

477

478

479

480

481

482

483

484

485

486

487

488

489

490

491

492

493

494

495

496

497

Abbot, J. M., Byrd-Bredbenner, C., Schaffner, D., Bruhn, C. M., \& Blalock, L. (2009). Comparison of food safety cognitions and self-reported food-handling behaviors with observed food safety behaviors of young adults. European journal of clinical nutrition, 63, 572-579.

Adak, G. K., Meakins, S. M., Yip, H., Lopman, B. A., \& O'Brien, S. J. (2005). Disease risks from foods, England and Wales, 1996-2000. Emerging Infectious Diseases, 11(3), $365-372$.

Ajzen, I. (1991). Attitudes, personality and behaviour. Milton Keynes: Open University Press.

Armitage, C. J., \& Conner, M. (2001). Efficacy of the theory of planned behaviour: A metaanalytic review. British Journal of Social Psychology, 40(4), 471-499.

Brennan, M., McCarthy, M., \& Ritson, C. (2007). Why do consumers deviate from best microbiological food safety advice? An examination of high-risk consumers on the island of Ireland. Appetite, 49(2), 405-418.

Byrd-Bredbenner, C., Abbot, J. M., \& Quick, V. (2010). Food Safety Knowledge and Beliefs of Middle School Children: Implications for Food Safety Educators. Journal of Food Science Education, 9(1), 19-30.

Byrd-Bredbenner, C., Maurer, J., Wheatley, V., Cottone, E., \& Clancy, M. (2007). Observed food safety behaviours of young adults. British Food Journal, 109(7), 519-530.

Chow, S., \& Mullan, B. (2010). Predicting Food Hygiene: An Investigation of Social Factors and Past Behaviour in an extended model of the Health Action Process Approach Appetite, 54, 126-133. 
Clayton, D. A., Griffith, C., \& Price, P. (2003). An investigation of the factors underlying consumers' implementation of specific food safety practices. British Food Journal, $105,434-453$.

Clayton, D. A., \& Griffith, C. J. (2008). Efficacy of an extended theory of planned behaviour model for predicting caterers' hand hygiene practices. International journal of environmental health research, 18(2), 83-98.

Clayton, D. A., Griffith, C. J., Price, P., \& Peters, A. C. (2002). Food handlers' beliefs and self-reported practices. International journal of environmental health research, 12(1), 25-39.

Cody, M., \& Hogue, M. (2003). Results of the home food safety - It's in your hands 2002 survey: Comparisons to the 1999 benchmark survey and healthy people 2010 food safety behaviors objective. Journal of the American Dietetic Association, 103(9), $1115-1125$.

Conner, M., \& Sparks, P. (2005). Theory of planned behaviour and health behaviour. In M. Conner \& P. Norman (Eds.), Predicting health behaviour: research and practice with social cognition models (pp. 170-222). Maidenhead, Berkshire: Open University Press.

Crerar, S. K., Dalton, C. B., Longbottom, H. M., \& Kraa, E. (1996). Foodborne disease: current trends and future surveillance needs in Australia. Medical Journal of Australia, 165(11-12), 672-675.

Desmarchelier, P. M. (1996). Foodborne disease: emerging problems and solutions. Medical Journal of Australia, 165(11-12), 668-671.

Dharod, J., Perez-Escamilla, R., Bermudez-Millan, A., Segura-Perez, S., \& Damio, G. (2004). Influence of the fight BAC! food safety campaign on an urban Latino 

134.

Fishbein, M., \& Ajzen, I. (2010). Predicting and changing behavior: The Reasoned Action Approach. New York: Psychology Press (Taylor \& Francis).

Food Authority NSW. (2008). Keeping food safe; key tips. In (Vol. 2008). Sydney: Food Authority.

Food Standards Agency. (2005). Improving Food Hygiene Awareness in the Home, through Schools and Local Initiatives: Developing a New Strategy. Local Initiatives. In. Cardiff: Food Hygiene Campaign, Welsh Consultation Event.

Food Standards Agency. (2009). Annual Report of the Chief Scientist 2008/09, 2009. In: Food Standards Agency.

Francis, J. J., Eccles, M. P., Johnston, M., Walker, A. E., Grimshaw, J. M., Foy, R., Kaner, E. F. S., Smith, L., \& Bonetti, D. (2004). Constructing questionnaires based on the theory of planned behaviour: A manual for health services researchers. In. Newcastle upon Tyne: Centre for Health Services Research.

Frewer, L., Shepherd, R., \& Sparks, P. (1994). The interrelationship between perceived knowledge and risk associated with a range of food-related hazards targeted at the individual, other people and society. Journal of Food Safety, 14, 19-40.

Fulham, E., \& Mullan, B. (2011). Hygienic Food-handling Behaviours: Attempting to bridge the Intention-Behaviour Gap using Aspects from Temporal Self Regulation Theory. Food Protection, 74(6), 925-932.

Giritlioglu, I., Batman, O., \& Tetik, N. (2011). The knowledge and practice of food safety and hygiene of cookery students in Turkey. Food Control, 22(6), 838-842.

Green, L. R., \& Selman, C. (2005). Factors impacting food workers' and managers' safe food preparation practices: a qualitative study. Food Protection Trends, 25(12), 981-990. 
547 Griffith, C., Mullan, B., \& Price, P. (1995). Food safety: implications for food, medical and behavioural scientists British Food Journal, 97(8), 23-28.

Griffith, C., Worsfold, D., \& Mitchell, R. (1998). Food preparation, risk communication and the consumer. Food Control, 9(4), 225-232.

551

552

553

554

555

556

557

558

559

560

561

562

563

564

565

566

567

568

569

570

Haapala, I., \& Probart, C. (2004). Food safety knowledge, perceptions, and behaviors among middle school students. Journal of Nutrition Education and Behavior, 36(2), 71-76.

Hall, G., \& Kirk, M. (2005). Foodborne illness in Australia. Annual incidence circa 2000. In: Canberra: Australian Department of Health and Ageing.

Hall, G., Kirk, M. D., Becker, N., Gregory, J. E., Unicomb, L., Millard, G., Stafford, R., Lalor, K., \& Group, O. W. (2005). Estimating foodborne gastroenteritis, Australia. Emerg Infect Dis, 11(8), 1257-1264.

Hanson, J., \& Benedict, J. (2002). Use of the Health Belief Model to Examine Older Adults' Food-Handling Behaviors. Journal of Nutrition Education and Behavior, 34(Supplement 1), S25-S30.

Harris, K., \& Mullan, B. (2009). Extending the Theory of Planned Behaviour: The Role of Habit, Anticipated Regret and Knowledge in Food Hygiene Behaviour. In The Australasian Society of Behavioural Health and Medicine (ASBHM) 7th Annual Scientific Conference. Brisbane, Australia.

Harrison, J. A., Mullen, P. D., \& Green, L. W. (1992). A meta-analysis of studies of the health belief model with adults. Health Education Research, 7, 107-116.

Jay, L. S., Comar, D., \& Govenlock, L. D. (1999). A Video Study of Australian Domestic Food-Handling Practices. Journal of Food Protection, 62(11), 1285-1296.

Kuttschreuter, M. (2006). Psychological determinants of reactions to food risk messages. Risk Analysis, 26(4), 1045-1057. 
Lobb, A., Mazzocchi, M., \& Traill, W. (2007). Modelling risk perception and trust in food safety information within the theory of planned behaviour. Food Quality and Preference, 18(2), 384-395.

McArthur, L., Holbert, D., \& Forsythe, W. (2006). Compliance With Food Safety Recommendations Among University Undergraduates: Application of the Health Belief Model. Family and Consumer Sciences Research Journal, 35(2), 160.

Mead, P., Slutsker, L., Dietz, V., McGCaig, L., Bresee, J., Shapiro, C., \& al., E. (1999). Food-related illness and death in the United States. Emerging Infectious Diseases, 5, 607-625.

Mente, A., de Koning, L., Shannon, H. S., \& Anand, S. S. (2009). A systematic review of the evidence supporting a causal link between dietary factors and coronary heart disease. Archives of internal medicine, 169(7), 659.

Milton, A., \& Mullan, B. (2010). Consumer food safety education for the domestic environment: A systematic review. British Food Journal, 112(9), 1003 - 1022.

Milton, A., \& Mullan, B. (2012). An application of the Theory of Planned Behavior - A randomized controlled food safety pilot. Health Psychology, 31(2), 250-259.

Mullan, B. (1998). Knowledge, beliefs and attitudes concerning food hygiene in children and young adults in south east Wales. Unpublished $\mathrm{PhD}$ thesis, University of Wales Institute, Cardiff.

Mullan, B. (2009). Using the Theory of Reasoned Action to Predict Safe Food Handling : Knowledge attitudes and social norms of children and young adults regarding food hygiene behaviour. Saarbruken: VDM Verlag Dr Muller Aktienesellschaft \& Co.

Mullan, B. (2010). Using Social cognition models to predict and design interventions to modify consumers' safe food handling behaviour. In F. Columbus (Ed.), Food Safety from Production to Consumption. New York: Nova Science Publishers, Inc. 
Mullan, B., \& Wong, C. L. (2009). Hygienic food handling behaviours. An application of the Theory of Planned Behaviour. Appetite, 52(3), 757-761.

Mullan, B., Wong, C. L., \& O'Moore, K. (2010). Predicting hygienic food handling behaviour: modelling the health action process approach. British Food Journal, 112 (11), 1216-1229

Osaili, T. M., Obeidat, B. A., Abu Jamous, D. O., \& Bawadi, H. A. (2011). Food safety knowledge and practices among college female students in north of Jordan. Food Control, 22(2), 269-276.

Quine, L., Rutter, D., \& Arnold, L. (1998). Predicting and understanding safety helmet use among schoolboy cyclists: A comparison of the theory of planned behaviour and the health belief model. Psychology \& Health, 13(2), 251-269.

Raab, C. A., \& Woodburn, M. J. (1997). Changing risk perceptions and food handling practices of Oregon household food preparers Journal of Consumer Studies \& Home Economics, 21, 117-130.

Redmond, E., \& Griffith, C. (2003a). Consumer Food Handling in the Home: A Review of Food Safety Studies. Journal of Food Protection, 66(1), 130-161.

Redmond, E., \& Griffith, C. (2004). Consumer perceptions of food safety risk, control and responsibility. Appetite, 43(3), 309-313.

Redmond, E. C., \& Griffith, C. J. (2003b). A comparison and evaluation of research methods used in consumer food safety studies. International Journal of Consumer Studies, 27(1), 17-33.

Rennie, D. M. (1995). Health education models and food hygiene education. The Journal of the Royal Society for the Promotion of Health, 115(2), 75-79.

Roseman, M., \& Kurzynske, J. (2006). Food safety perceptions and behaviors of Kentucky consumers. Journal of Food Protection, 69(6), 1412-1421. 
Rosenstock, I. M. (1974). Historical Origins of the Health Belief Model. Health Education Monographs, 2(4).

Ryan, M. J., Wall, P. G., Gilbert, R. J., Griffin, M., \& Rowe, B. (1996). Risk factors for outbreaks of infectious intestinal disease linked to domestic catering. Communicable Disease Report, 6(13), R179-183.

Schwarzer, R., Sniehotta, F. F., Lippke, S., Luszczynska, A., Scholz, U., Schüz, B., Wegner, M., \& Ziegelmann, J. P. (2003). On the assessment and analysis of variables in the health action process approach: Conducting an investigation. Berlin: Freie Universität Berlin. Zugriff am, 5, 2008.

Seaman, P., \& Eves, A. (2010). Efficacy of the theory of planned behaviour model in predicting safe food handling practices. Food Control, 21(7), 983 - 987.

Shapiro, M. A., Porticella, N., Jiang, L. C., \& Gravani, R. B. (2011). Predicting intentions to adopt safe home food handling practices. Applying the theory of planned behavior. Appetite, 56(1), 96-103.

Soon, J. M., Baines, R., \& Seaman, P. (2012). Meta-Analysis of Food Safety Training on Hand Hygiene Knowledge and Attitudes among Food Handlers. Journal of Food Protection, 75(4), 793-793.

Wilcock, A., Pun, M., Khanona, J., \& Aung, M. (2004). Consumer attitudes, knowledge and behaviour: a review of food safety issues. Trends in Food Science \& Technology, $15(2), 56-66$. 
Table 1. Demographics of sample

\begin{tabular}{lll}
\hline Demographics & & Percentage \\
\hline Gender & Males & $44 \%$ \\
& Females & $56 \%$ \\
Country & Australia & $47 \%$ \\
& UK & $51 \%$ \\
Living situation & With parents & $96 \%$ \\
& Other & $4 \%$ \\
SES from father's occupation & High & $50.7 \%$ \\
& Middle & $31.5 \%$ \\
& Low & $16.2 \%$ \\
SES from mother's occupation & High & $49.3 \%$ \\
& Middle & $24 \%$ \\
& Low & $26.9 \%$ \\
& Australian & $47 \%$ \\
Ethnicity & North-West European & $48 \%$ \\
& Asian & $2 \%$ \\
& & \\
& &
\end{tabular}

Note: percentages may not add to 100 due to missing data 
Table 2. Pearson's correlations for TPB variables, knowledge and risk

\begin{tabular}{|c|c|c|c|c|c|c|}
\hline & SN & $\mathrm{PBC}$ & Risk & Intention & Behavior & Knowledge \\
\hline ATT & $.494 * *$ & $.454 * *$ & $.170-$ & $.458^{*}$ & $.167 *$ & $.188^{*}$ \\
\hline SN & - & $.674 * *$ & $.328 * *$ & $.746 * *$ & $.307 * *$ & $.199 * *$ \\
\hline PBC & - & - & $.441 * *$ & $.708 * *$ & $.480 * *$ & $.157 *$ \\
\hline Risk & - & - & - & $.405^{* *}$ & $.435^{* *}$ & .067 \\
\hline Intention & - & - & - & - & $.437 * *$ & $.202 * *$ \\
\hline Behavior & - & - & - & - & - & $.138 *$ \\
\hline
\end{tabular}


Table 3. Hierarchical regression analysis: TPB variables and food safety knowledge predicting intention

\begin{tabular}{|c|c|c|c|c|c|}
\hline & Variable & $\beta$ & $\mathrm{t}$ & $p$ & $\mathrm{R}^{2}$ \\
\hline Step 1 & Knowledge & .202 & 2.92 & $.004 * *$ & .041 \\
\hline \multirow[t]{5}{*}{ Step 2} & Knowledge & .043 & .974 & .331 & \\
\hline & Attitude & .053 & 1.05 & .296 & \\
\hline & SN & .446 & 7.35 & $<.001 * *$ & \\
\hline & PBC & .384 & 6.506 & $<.001 * *$ & \\
\hline & & & & & .637 \\
\hline \multirow[t]{6}{*}{ Step 3} & Knowledge & .006 & 1.24 & .318 & \\
\hline & Attitude & .063 & .924 & .238 & \\
\hline & SN & .387 & 7.23 & $<.001 * *$ & \\
\hline & PBC & .354 & 5.49 & $.000^{* * *}$ & \\
\hline & Risk & .117 & 2.49 & $.014^{*}$ & \\
\hline & & & & & .648 \\
\hline
\end{tabular}


Table 4. Hierarchical regression: TPB variables, knowledge and interaction

\begin{tabular}{llllll}
\hline & Variable & $\beta$ & $\mathrm{t}$ & $\mathrm{p}$ & $\mathrm{R}^{2}$ \\
\hline Step 1 & Knowledge & .138 & 1.977 & $.049^{*}$ & .014 \\
\hline Step 2 & Knowledge & .052 & .801 & .424 & \\
& Intention & .427 & 6.60 & $<.001^{* *}$ & .247 \\
\hline Step 3 & Knowledge & .050 & .793 & .429 & \\
& Intention & .183 & 2.10 & $.038^{*}$ & \\
& PBC & .337 & 3.87 & $<.001^{* *}$ & \\
& Int X Knowledge & -.005 & -.558 & .577 & .253 \\
& & & & & \\
\end{tabular}

Note: $\mathrm{DV}=$ Behavior; overall $\mathrm{R}^{2}=.25 ; * *$ denotes significance at the .01 level 
References omitted from Author Final Draft:

Ajzen, I. (2002). Constructing a TPB questionnaire: Conceptual and methodological considerations. Retrieved April, 7, 2007.

Sparks, P. (1994). Attitudes towards food: Applying, assessing and extending the theory of planned behaviour. 